Ensino, Saúde e Ambiente - v. 14 n. esp. (2021): Dossiê Paulo Freire para além dos 100 anos: construir utopias, transformar a realidade, p. 685-708.

Estética, Cinema, Teatro, Comunicação

\title{
Ambiente y Cotidianidad como projeto educativo de ação dialógica e cultural
}

\author{
Environment and Everyday Life as a dialogic and cultural action \\ educational project
}

\author{
María Angélica Mejía-Cáceres ${ }^{1}$; Bruno Andrade Pinto Monteiro; Monica Lopes Folena Araújo \\ ${ }^{1}$ Doutora em Educação em Ciências e Saúde, Universidade Federal Rural de Pernambuco, Recife, Pernambuco, Brasil - E- \\ mail: mariaangelicamejiacaceres@gmail.com/ORCID http://orcid.org/0000-0003-3486-1952 \\ 2 Doutor em Educação em Ciências e Saúde, Universidade Federal do Rio de Janeiro, Rio de Janeiro, Rio de Janeiro, Brasil - \\ E-mail: bpmonteiro@gmail.com / ORCID https://orcid.org/0000-0001-8933-5816 \\ 3 Doutora em Educação, Universidade Federal Rural de Pernambuco, Recife, Pernambuco, Brasil - E-mail: \\ $\underline{\text { monica.folena@ufrpe.br / ORCID http://orcid.org/0000-0002-0688-9782 }}$
}

\author{
Palavras-chave: \\ ambiente y cotidianidad; \\ podcast; ação dialógica; \\ Paulo Freire; unidades \\ pedagógicas.
}

RESUMO: Considerando o aumento do uso dos programas de podcast e seu fácil acesso, assim como um meio para complementar o processo de aprendizagem, nos interessamos em construir uma proposta que permitisse contribuir para uma educação ambiental autêntica, e humanizadora em termos freireanos. Nesse sentido, este artigo apresenta um projeto baseado em situações comunicativo-educativas freireanas para o uso do programa de podcast Ambiente y Cotidianidad em espaços educativos tendo como questão motivadora: de que maneira o podcast pode contribuir para uma educação ambiental mais autêntica e humanizadora? A partir de obras de Paulo Freire, estabelecemos situações comunicativo-educativas, de acordo com temas como o ser humano como um ser de relações no mundo da natureza e cultura, educação dialógica, consciência crítica, educação como prática da liberdade. Entre as unidades pedagógicas estabelecidas buscou-se utilizar o background cultural, o ser humano como um ser criador e recriador na realidade e na compreensão dela, recriar a imagem do sujeito consumidor pela imagem do cidadão, a esperança de transformar nossos hábitos depredadores pela desesperança, saber superado como ignorância, diversidade e amor, entre outros. Concluímos que é possível considerar o podcast com um projeto dialógico, na medida em que se configura como uma linguagem que aproxima as pessoas, conectando seus mundos, assim como, considerar algumas categorias freirianas como a humanização, o diálogo, a criticidade e a criatividade; permite-nos inferir que é viável, contribuir no incremento das conexões e parcerias entre espaços informais e formais em processos educativos emancipatórios e libertadores. 
Ensino, Saúde e Ambiente - v. 14 n. esp. (2021): Dossiê Paulo Freire para além dos 100 anos:

construir utopias, transformar a realidade, p. 685-708.

\author{
Estética, Cinema, Teatro, Comunicação
}

\begin{abstract}
Keywords: environment and everyday life; Podcast; dialogic action; Paulo Freire; teaching units.
\end{abstract}

\begin{abstract}
Podcast consumption is growing as the result of their easy access as well as the possibility of their use as an aid in the learning process. Considering this increase in consumption, we were interested in creating a proposal that would allow us to contribute to an authentic environmental and humanizing educational experience in Freirean terms. This article presents a project based on Freirean communicativeeducational situations using the ambiente y Cotidianidad (Environment and Everyday Life) podcast program in educational spaces. The guiding question of this article is: how can the podcast contribute to a more authentic and humanizing environmental education? Based on Paulo Freire's work, we establish communicative-educational situations according to themes such as the human being as a being of relationships in the world of nature and culture, dialogic education, critical awareness, education as a practice of freedom. Among the pedagogical units established, we seek to use the cultural background, the human being as a creator and recreator in reality and its understanding, recreating the image of the consumer subject through the image of the citizen, the hope of transforming our predatory habits through hopelessness, knowledge overcome as ignorance, diversity and love, among others. We conclude that it is possible to consider the podcast as a dialogic project, as it is configured as a language that brings people together, connecting their worlds, as well as considering some Freirian categories such as humanization, dialogue, criticality and creativity; it allows us to infer that it is feasible to contribute to increasing connections and partnerships between informal and formal spaces in emancipatory and liberating educational processes.
\end{abstract}

\title{
INTRODUÇ̃̃̃O
}

A Educação em Ciências e a Educação Ambiental constituem áreas importantes que têm sido mobilizadas a promover ações de divulgação científica, no sentido de fazer chegar à sociedade as práticas da ciência, suas descobertas e construções. Desse modo, tanto a educação como a divulgação científica não são atividades que correspondem unicamente à lógica ou processos cognitivos, mas também, estão associadas e relacionadas com a interação e as culturas de grupos sociais. Segundo Bizzo (2013), nesses grupos existem processos denominados de "habitualização" que correspondem às ações repetidas com frequência que podem criar um certo padrão. Nesse sentido, existem atos habitualizados que tornam-se rotina.

Reiterando, podemos encontrar na sociedade atos habitualizados associados ao uso da mídia tradicional, tais como a televisão e o rádio. Desse modo, com o passar do tempo,observam-se processos de midiatização, que correspondem às interações com novos meios de base digital e computacional (GOES, 2019), como a internet e outros canais de comunicação, os quais têm aberto espaços significativos nas rotinas das pessoas. Porém, estes meios de comunicação podem responder aos interesses da indústria cultural, a qual converte desde os bens culturais até a organização cultural em mercadorias, assim como, contribui numa espécie de domínio da sociedade pelo mecanismo da "semiformação" mediante a produção e circulação de conteúdos irracionais e conformistas (ADORNO, 1947). 
Ensino, Saúde e Ambiente - v. 14 n. esp. (2021): Dossiê Paulo Freire para além dos 100 anos: construir utopias, transformar a realidade, p. 685-708.

\section{Estética, Cinema, Teatro, Comunicação}

Portanto, a indústria da mídia contribui para a construção de significação do mundo ou da construção social da realidade; essa criação de sentido se dá por "tomar a atitude do outro"(MARROQUIM, 2010), constituindo-se numa prática que pode ser vista como colonizadora, por isso, podemos vincular o uso e consumo das mídias às dimensões da colonialidade, a do poder (QUIJANO, 2010), do saber (LANDER, 1993) e do ser (MALDONADO-TORRES, 2009); o que significa que as mídias podem participar numa malha de relações sociais de exploração, dominação e conflito para assegurarem o controle social.

Atualmente, novos cenários de interação e produção aberta de conteúdo tem emergido, como é o caso dos podcasts. Segundo Pollock (2010), o podcast é uma linguagem que pode ocupar as atividades cotidianas sendo capaz de influenciar milhões de pessoas. Algumas definições simples, entendem este recurso como uma gravação digital que se encontra disponível na internet para se baixar e outras definições mais elaboradas, fazem referência a um arquivo de mídia transmitido via feed RSS (Real Symple Syndication). Sobretudo, para alguns outros usuários o referido recurso não se refere somente ao áudio, mas também, a interação com os seus conteúdos via RSS (JESUS, 2014; BIERMAN;VALENTINO, 2011).

A distribuição social do podcast tem aumentado através do tempo. No Brasil, depois de 2004, aumentaram os programas consideravelmente e, em 2013, tinham se identificado aproximadamente 255 podcasters e já para 2018, ao redor de 1278, segundo a PodPesquisa ${ }^{1}$

Essa emergência de uma nova linguagem nos chama a atenção, já que nos perguntamos, qual seria o potencial de comunicação do podcast? sobretudo, considerando o que afirma Freire (2017), “o que caracteriza a comunicação enquanto este comunicar comunicando-se, é que ela é diálogo, assim como o diálogo é comunicativo (p. 87). Freire faz ênfase na importância do signo compartilhado para que possa existir compreensão entre os sujeitos, o que faz diferença entre a extensão do pensamento de um sujeito até o outro e do diálogo que se dá na comunicação dos sujeitos pensantes a propósito do pensado.

De acordo com o contexto anterior, é importante conhecer os elementos que interferem na formação do cidadão, desde o pensamento que começa a se construir, até as linguagens que medeiam e as atuações que geram relações, por exemplo, com a dimensão ambiental, dado às diferentes problemáticas e crises ambientais como o desmatamento, a crise hídrica, a emergência climática, o ecoetnogenocidio (QUIÑONEZ, 2018; CASTRO; MONTEIRO,

\footnotetext{
1 PodPesquisa é uma iniciativa de produtores de conteúdo podcast e veículos de imprensa para mapeamento e compreensão do crescimento e penetração da mídia podcast no Brasil.
} 
Ensino, Saúde e Ambiente - v. 14 n. esp. (2021): Dossiê Paulo Freire para além dos 100 anos: construir utopias, transformar a realidade, p. 685-708.

\section{Estética, Cinema, Teatro, Comunicação}

2020), mas também, os enfraquecimentos das legislações e fiscalizações ambientais no paíse nos outros países latinoamericanos.

De acordo ao discutido nesta até aqui e a partir do pensamento de Freire nos perguntamos: como o podcast pode contribuir para uma educação ambiental mais autêntica, humanizadora e não restritiva?

Para responder a este problema de pesquisa analisamos o projeto podcast conhecido como: "Ambiente y cotidianidad", criado durante a pandemia provocada pelo coronavírus (COVID-19).

\section{PODCAST E EDUCAÇÃO}

Entendemos o podcast, como uma linguagem que dispõe conteúdo de áudio, disponível em arquivo ou streaming. A vantagem do podcast é que ele é um recurso sob demanda, ou seja, o usuário ouve quando quer. Ele pode ser ouvido em vários dispositivos e fato que ajudou a disseminar seu uso e aumentar sua popularidade.

O termo podcast foi criado em 2004 e nasceu da união das palavras iPod (tocador de música da Apple) e broadcasting (transmissão). Anteriormente, foi explicado que este recurso é transmitido via RSS, que significa para Really Simple Syndication, um formato para distribuir conteúdo na internet. É usado para disseminar informações atualizadas com frequência para usuários que se inscreveram na fonte do conteúdo. O formato permite que o conteúdo seja distribuído sem a necessidade de navegador, por meio de programas chamados agregadores de notícias, voltados para a leitura de conteúdo RSS, como os aplicativos: Mozilla Firefox, Thunderbird ou Akregator, entre outros.

Existem diferentes formatos dos programas dos podcasts, entre eles: entrevista, informativo, painel e monólogo. A escolha depende dos objetivos do produtor, ou na linguagem deste campo, o podcaster. O podcast, não se resume ao processo de fazer áudios, mas implica em todo um planejamento, que inclui definir os objetivos, definir o público, eleger o tipo de podcast, definir sua identidade, criar nome, desenhar o logo, e determinar a duração e frequência dos episódios. Lembremos que o podcast faz referência a um programa como um todo, composto por episódios que podem abordar diferentes temáticas, esses episódios devem ter spot (texto explicativo), apresentações, um corpo, agradecimento e despedida. Além de precisar de um local de gravação, de um software de comunicação, banda sonora, microfone e estrutura; os programas são importantes para nivelar o volume das vozes, editar, incluir música, eliminar ruídos, entre outros aspectos. 
Ensino, Saúde e Ambiente - v. 14 n. esp. (2021): Dossiê Paulo Freire para além dos 100 anos: construir utopias, transformar a realidade, p. 685-708.

\section{Estética, Cinema, Teatro, Comunicação}

Os programas podcast devem ter um servidor para sua hospedagem. Existem diversos serviços gratuitos e pagos, por exemplo, soundcloud, podbean, spreaker, captivate, entre outros.

Segundo alguns pesquisadores como Freire (2015) o primeiro podcast brasileiro foi o Digital Minds, produzido por Danilo Medeiros e publicado em 21 de outubro de 2004. Nesse contexto, essaa autora afirma que historicamente,

[...] A partir de 2006, a mídia foi se desenvolvendo e teve um destaque especial em 2008, quando o Prêmio iBest incluiu a categoria podcast (votação popular) e houve ainda o Prêmio Podcast, que condecorou várias categorias do meio. Muitos dos podcasts nascidos e premiados após 2005 , na chamada segunda geração brasileira, existem até hoje e são bastante consolidados. São exemplos o Nerdcast e o Rapaduracast, ambos originados em 2006 e com público atual médio de mais de 150 mil downloads por episódio (FREIRE, 2015, p. 39)

Ainda que no Brasil a produção e uso do podcast siga crescendo, em países como Estados Unidos, Austrália e no Reino Unido as universidades fazem uso extensivo deste recurso. Estudos mostram a importância de não considerar o podcast como um substituto de recursos conhecidos, mas como um meio que complementa os processos de aprendizagem e que motiva, por exemplo, iniciativas de assistir palestras, fazer perguntas ao professor, de conhecer o professor, educador ou podcaster e seus trabalhos (NATAATMADJA, DYSON; 2008). Isso chama a atenção para o fato que o programa podcast por si só, não pode desenvolver uma aprendizagem profunda e crítica, sobretudo, dependerá de como os educadores fazem o uso dele, já que podem usar para atividades memorísticas, mediante a repetição do conteúdo, até atividades inovadoras para se desenvolver um pensamento crítico.

Rajic (2013) propõe mais de 10 estratégias para o uso de podcasts em contexto educativo, entre elas destacam-se: incorporar exemplos e sujetos de interesse dos ouvintes; o uso de pausas de pensamento, na qual o professor pode perguntar aos estudantes sobre um ponto em particular, permitindo aos estudantes refletirem sobre a temática; fazer perguntas ao final etc. $\mathrm{O}$ autor afirma que seria importante que os educadores conseguissem desenvolver seus próprios podcasts, mas ao mesmo tempo, existem websites com conteúdo podcast de qualidade que podem ser utilizados nos processos educativos e de divulgação da ciência. Adicionalmente, na literatura podemos encontrar diversos usos educativos dos podcasts, como por exemplo, gravar atividades, gravar reflexões sobre uma temática aprendida, postar informações sobre atividades semanais para que familiares e estudantes consigam ouvir, anotar, entre outras aplicações (ARISTIZABAL, 2021). 
Ensino, Saúde e Ambiente - v. 14 n. esp. (2021): Dossiê Paulo Freire para além dos 100 anos: construir utopias, transformar a realidade, p. 685-708.

Estética, Cinema, Teatro, Comunicação

\section{O DIÁLOGO COMO PRÁTICA EDUCATIVA E DE LIBERDADE}

O binômio diálogo/ dialogicidade é essencial na obra freiriana na medida em que a possibilidade de se pensar em uma educação libertadora parte de uma concepção de diálogo que se amplia profundamente em direção ao outro, ao inacabamento e ao descontrole enunciativo, características inerentes ao ato comunicativo. Para Freire, o diálogo possui um caráter dialético-problematizador, pois é por meio do diálogo que temos a chance de experimentar o distanciamento necessário para observar o mundo e a nossa própria existência. É a experiência de se enxergar a partir de uma triangulação, as transformações sociais em processo, a historicidade e o inacabamento da realidade.

Além dessa perspectiva, cabe-nos destacar que a palavra, tradicionalmente concebida como um veículo ou um meio sígnico, na concepção de Freire não se restringe aos significados estáveis. A palavra funciona como um portal ou um instrumento potente de pronunciar o mundo. O mundo pela experiência de se transpor em palavras diante do desafio do diálogo, é modificado ou ressignificado constantemente numa teia de significações que se disputam e se estabilizam no contexto na arena discursiva do ato comunicativo. Nas palavras de Paulo Freire "Existir humanamente, é pronunciar o mundo, é modificá-lo. O mundo pronunciado, por sua vez, se volta problematizado aos sujeitos pronunciantes, a exigir deles um novo pronunciar" (FREIRE, 1987, p. 44).

Humanos se constituem na arena do diálogo, mediatizados pelo mundo no exercício da palavra. É preciso reconhecer a dimensão constitutiva do discurso, assim como Paulo Freire o faz. Há no ato do diálogo um intenso processo de ação-reflexão, uma práxis, um trabalho de transformação do mundo por meio de interlocuções que não restringem-se aos interlocutores presentes. Há interlocutores do passado, há outros interlocutores que fazem-se presentes nas vozes dos falantes e também há o mundo. O diálogo, alcança a dimensão dialógica nesse processo de mediatização pelo mundo. É nesse caminho que Freire demonstra que a interlocução vai além das relações eu-tu.

Não é do silêncio que os homens se fazem, mas na palavra, no trabalho, na açãoreflexão (FREIRE, 1987, p.44).

Mas, se dizer a palavra verdadeira, que é trabalho, que é práxis, é transformar o mundo, dizer a palavra não é privilégio de alguns homens, mas direito de todos os homens. Precisamente por isto, ninguém pode dizer a palavra verdadeira sozinho, ou dizê-la para os outros, num ato de prescrição, com o qual rouba a palavra aos demais. 
Ensino, Saúde e Ambiente - v. 14 n. esp. (2021): Dossiê Paulo Freire para além dos 100 anos: construir utopias, transformar a realidade, p. 685-708.

\section{Estética, Cinema, Teatro, Comunicação}

O diálogo é este encontro dos homens, mediatizados pelo mundo, para pronunciá-lo, não se esgotando, portanto, na relação eu-tu. (FREIRE, 1987, p. 45).

Outro ponto importante é que a palavra incorpora a tarefa de traduzir e ao mesmo tempo construir o mundo. É uma concepção com que impõe a palavra a práxis, o fazer, a ação e o trabalho. Pronunciar é um ato revolucionário de agir no mundo, modificando-o. As contradições, os conflitos, os valores e as ideologias encontram-se no diálogo ampliando a ideia de uma simples troca de significados. Nesse sentido, Paulo Freire reitera que o diálogo é existencial. É a condição de se viver e portanto, o ato de educar é revolucionário no sentido de resgatar a capacidade de diálogo dos interlocutores que perderam essa capacidade ou que estão dando seus primeiros passos na leitura e pronúncia do mundo. Nesse sentido, Paulo Freire, sistematiza essas ideias quando afirma em Pedagogia do Oprimido que

\footnotetext{
Se é dizendo a palavra com que, "pronunciando" o mundo, os homens o transformam, o diálogo se impõe como caminho pelo qual os homens ganham significação enquanto homens. Por isso, o diálogo é uma exigência existencial. E, se ele é o encontro em que se solidariza o refletir e o agir de seus sujeitos endereçados ao mundo a ser transformado e humanizado, não pode reduzir-se a um ato de depositar idéias de um sujeito no outro, nem tampouco tornar-se simples troca de idéias a serem consumidas pelos permutantes (FREIRE, 1987, p. 45).
}

\section{A ABERTURA COMO UM ATO DIALÓGICO}

Em Pedagogia da Autonomia, Freire nos traz inúmeras lições importantes que apontam para compreensão de uma pedagogia a partir de uma perspectiva dialógica que parte de um processo de dialogicidade. $\mathrm{O}$ autor nos coloca o imperativo de que o ato de "ensinar exige disponibilidade para o diálogo", ou seja, fala de uma forma particular de compreender essa disponibilidade como ato de entrega ao outro/a, ou em outros termos, uma "corporeificação" que consiste numa forma de impregnar a palavra durante o ato comunicativo com a entrega do corpo e com a própria vida. Nesse sentido, reitera-se que "Testemunhar a abertura aos outros, a disponibilidade curiosa à vida, a seus desafios, são saberes necessários à prática educativa" (FREIRE, 1996, p. 137).

Abertura, inacabamento e inconclusão, constituem-se a bases do pensamento freiriano que são indispensáveis de uma relação que propõe-se dialógica. No contexto do ato comunicativo ou educativo, estar aberto ao inesperado, torna-se mais que uma possibilidade, torna-se, uma aventura em direção ao que não está previsto ou controlado. Ou seja, instaura-se de forma emergente caminhos pedagógicos e comunicativos não prescritos ou pré-definidos, 
Ensino, Saúde e Ambiente - v. 14 n. esp. (2021): Dossiê Paulo Freire para além dos 100 anos: construir utopias, transformar a realidade, p. 685-708.

\section{Estética, Cinema, Teatro, Comunicação}

por um currículo normativo, por exemplo, ou por outros tipos de roteiros que se traduzem em narrativas estagnadas historicamente. Para Freire, os educandos/as nesta perspectiva deveriam "Viver a abertura respeitosa aos outros e, de quando em vez, de acordo com o momento, tomar a própria prática de abertura ao outro como objeto da reflexão crítica deveria fazer parte da aventura docente" (FREIRE, 1996, p. 70/71).

Além dessa perspectiva de abertura, Freire em outro trecho, nos aponta para uma dimensão ética e estética que se coloca como uma condição ao diálogo na medida em que há uma postura constante de respeito ao outro, ao mesmo tempo, em que se considera como boniteza o ato de dialogar-ensinar. Em suas palavras, "A razão ética da abertura, seu fundamento político, sua referência pedagógica; a boniteza que há nela como viabilidade do diálogo" (FREIRE, 1996. p. 70).

Retomando a ampliação da experiência da abertura ao que é imprevisto, Freire destaca a importância de se abrir ao mundo num processo transgressivo de busca pela incompletude. Somos seres inacabados que estamos em construção, inseridos no mundo e cercados por pessoas num processo incessante de aprimoramento ético, estético, moral e afetivo. Da forma como colocam Trombetta e Trombetta (2010, p. 221), "Para nós, os seres humanos, o processo de conquista de nossa humanidade nunca está pronto. Nenhum humano é jamais tudo o que pode ser. Há sempre mais, a saber, a amar e fazer”. Reiterando, esta concepção Paulo Freire, conclui que

\footnotetext{
O cão e a árvore também são inacabados, mas o homem se sabe inacabado e por isso se educa. Não haveria educação se o homem fosse um ser acabado. O homem pergunta-se: quem sou? de onde venho? onde posso estar? O homem pode refletir sobre si mesmo e colocar-se num determinado momento, numa certa realidade: é um ser na busca constante de ser mais e, como pode fazer esta auto-reflexão, pode descobrir-se como um ser inacabado, que está em constante busca. Eis aqui a raiz da educação. (FREIRE, 1979, p. 14)
}

Dessa forma, admitimos que os processos educativos ou voltados para divulgação da ciência fundam-se na incompletude e inconclusão. É uma prerrogativa da humanidade e que instaura o ato educativo como condição histórica essencial à existência que nos projeta a possibilidade de buscarmos no futuro aquilo que poderemos ser. A busca pela completude nos impõe a incompletude num constante processo de amadurecimento alteritário que conhecemos como educação. Nesses caminhos e buscas, o projeto Ambiente y Cotidianidad se coloca como uma estratégia de ação dialógica que busca fomentar diálogos, por meio de podcasts, que fomentem a construção de um novo futuro que se situa numa perspectiva que não está prevista 
Ensino, Saúde e Ambiente - v. 14 n. esp. (2021): Dossiê Paulo Freire para além dos 100 anos: construir utopias, transformar a realidade, p. 685-708.

\section{Estética, Cinema, Teatro, Comunicação}

ou acabada. Um futuro que não seja a continuidade do que a busca desenfreada do capital plasma agora em nossas sociedades, mas um futuro de possibilidades alicerçado em uma busca constante por justiça ambiental, social e climática e que nos permita "sermos mais humanos do que somos", conforme destacam Trombetta e Trombetta (2010, p. 221), em sintonia com a nossa mãe terra a partir do que o pensamento freireano nos definiu como humanização.

\section{O PROGRAMA PODCAST AMBIENTE Y COTIDIANIDAD}

$\mathrm{Na}$ presente era digital, a adequação de espaços para a difusão do conhecimento científico e acadêmico é uma necessidade. Incursionar nos espaços digitais para ampliar o acesso do público a informação passou a ser uma tarefa importante para diferentes grupos. Portanto, compreender estes espaços como ferramentas que dinamizam o saber, é elementar, e mais ainda, na conjuntura atual de pandemia que impulsionou o uso das redes virtuais.

O projeto podcast "Ambiente y cotidianidad ${ }^{2 "}$ (Environment and Everyday Life ${ }^{3}$ ) foi pensado como um cenário dialógico para alcançar outros espaços e outros públicos. O programa surge durante a primeira quarentena da pandemia no Brasil, ou seja, no mês de abril de 2020, ao refletir no papel dos professores e dos pesquisadores na comunicação da ciência e de suas pesquisas, relacionada concretamente em uma realidade histórica, social e cultural dos cidadãos. Nesse sentido, esta iniciativa buscou ir além das leituras discutidas num grupo de pesquisa e seus projetos; apresentando questões da vida diária, vários avanços da ciência e da área de educação ambiental de um modo que pudesse ser compreendido facilmente pela população. A iniciativa partiu dos seguintes pressupostos: de que há na sociedade uma falta de cultura socioambiental que permita repensar-nos como seres plenos, históricos biológicos, sociais, políticos e culturais; que estamos imersos numa sociedade líquida, e que, de acordo com Bauman (2001) torna-se necessário utilizar meios de comunicação de acordo com a mobilidade própria da sociedade para fazer educação, divulgação científica e ativismo ambiental; e a necessidade de ser um canal de referência gerenciado por uma mulher e contribuir no empoderamento das mesmas.

O referido programa adotou objetivos cognitivos, atitudinais e sensitivos. Dentro dos objetivos cognitivos, se pretendeu contribuir para a compreensão de temáticas socioambientais

\footnotetext{
${ }^{2}$ Disponível em: https://www.spreaker.com/show/ambiente-e-cotidianidade

${ }^{3}$ Disponível em: https://www.spreaker.com/show/environment-and-everyday-life
} 
Ensino, Saúde e Ambiente - v. 14 n. esp. (2021): Dossiê Paulo Freire para além dos 100 anos: construir utopias, transformar a realidade, p. 685-708.

\section{Estética, Cinema, Teatro, Comunicação}

da atualidade numa linguagem cotidiana e de maneira curta, convertendo o conhecimento complexo e pouco familiarizado à sociedade a um discurso sintético, de fácil entendimento e de ampla dialogicidade. Como objetivo atitudinal assumimos a possibilidade de abordar conhecimentos que pudessem ser utilizados no dia a dia e como objetivo sensitivo provocar uma reflexão ou um olhar mais atento dos ouvintes para as questões sensíveis apresentadas no sentido de despertar a solidariedade, respeito, ajuda e colaboração pelos outros e outras.

O programa está estruturado por episódios de curta duração permitindo assim uma rápida difusão da informação nas plataformas como as redes sociais (ver figura 1 - o programa nos três podcasts). Os episódios são apresentados mediante dois formatos: o primeiro deles são monólogos realizados pela criadora, os quais são organizados previamente mediante um roteiro que considera aspectos da retórica; já no segundo formato, são convidados/as, os quais se caracterizam por serem especialistas e com um alto grau de reputação na temática, sendo de diferentes países. Por isso, os/as convidados/as discutiram e compartilharam informações relacionadas às questões atuais, como por exemplo a COVID-19. Além disso, foram criadas campanhas, como o mês de empoderamento feminino, o mês de decolonialidade e o mês da mudança climática.

Figura 1: Programa Ambiente y Cotidianidad nos três podcasts.

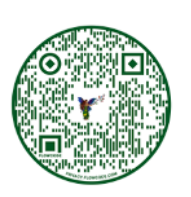

Español

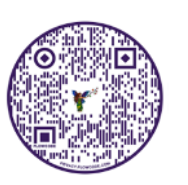

Português

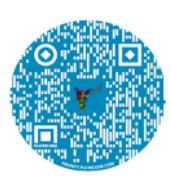

English
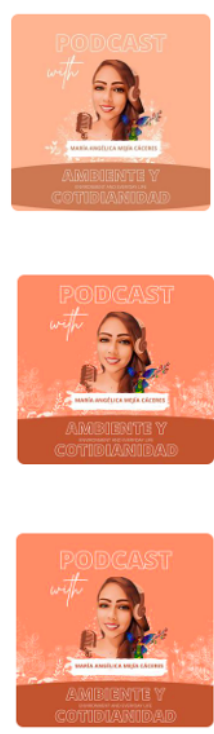

\section{Ambiente y Cotidianidad}

Reflexionaremos sobre aspectos de nuestro día a día, siempre vinculándolos a cuatro dimensiones: 1) estructura, 2) salud, 3) cultura y 4) ambiente. A través de preguntas invitaremos a modificar cie...
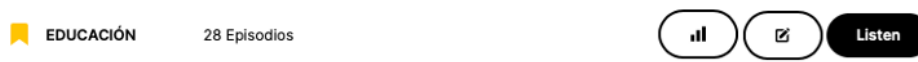

\section{Ambiente y Cotidianidad Português}

Vamos refletir sobre aspectos do nosso dia a dia, sempre vinculando-os a quatro dimensões: 1) estrutura, 2) saúde, 3) cultura e 4) ambiente. Por meio de perguntas, convidaremos a modificar certos h...

EDUCACIÓN 28 Episodios

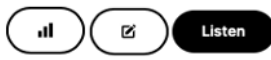

Environment And Everyday Life

We will reflect on aspects of our day to day, always linking them to four dimensions: 1) structure, 2) health, 3) culture and 4) environment. Through questions we will invite to modify certain habi...

EDUCACIÓN 10 Episodios

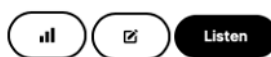

Por se tratar de um podcast ibero-americano, contamos com episódios principalmente em português e em espanhol ${ }^{4}$, e aos poucos estes são traduzidos ao inglês, portanto, o programa contou com uma equipe de voluntários para fazer a voz dos/as convidados/as no outro idioma

\footnotetext{
${ }^{4}$ Disponível em https://www.spreaker.com/show/ambiente-y-cotidianidad
} 
Ensino, Saúde e Ambiente - v. 14 n. esp. (2021): Dossiê Paulo Freire para além dos 100 anos: construir utopias, transformar a realidade, p. 685-708.

\section{Estética, Cinema, Teatro, Comunicação}

caso o/a convidado/a não soubesse falar em mais de uma língua. Os podcasts pretenderam romper fronteiras ao serem publicados em diferentes idiomas (ver figura 2 - identidade do programa Ambiente Y Cotidianidad). Baseando-se nos valores fundamentais para humanidade como dialogicidade, equidade, justiça social, respeito pela diversidade cultural, o projeto buscou abrir espaço para convidados/as de diferentes comunidades étnicas, e/ou de nacionalidades diversas.

Figura 2: Identidade do programa Ambiente y Cotidianidad.

\section{Ambiente y Cotidianidad}

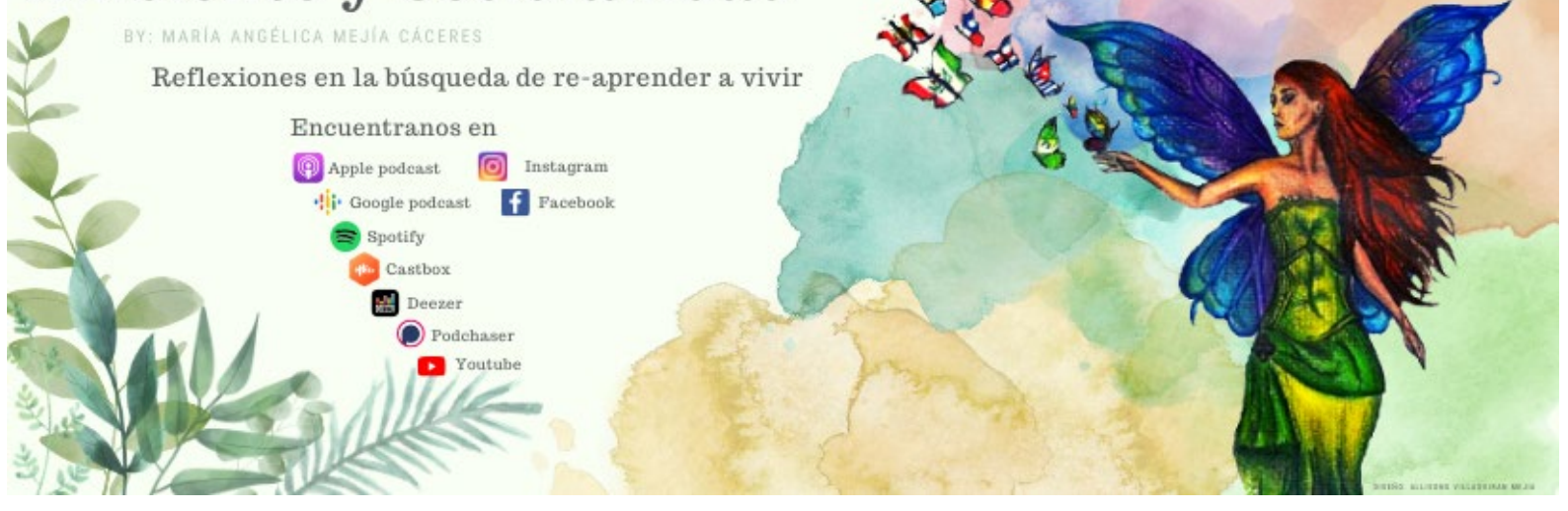

Essa valorização regional foi trabalhada desde o desenho da logo, onde se desenvolveu uma perspectiva estética, como uma maneira de abraçarmos as diferentes construções culturais que têm sido base do pensamento e materialização dos podcasts. A logo tem um desenho pintado a óleo num cenário natural, no qual há uma fada, que simboliza Gaia, a mãe Terra, a mulher, a pachamama. Elas são símbolos de liberdade de desfrutar a conexão com a Terra, com nossa moradia. Suas mãos simbolizam os instrumentos do conhecimento estético, poético e científico, com a intervenção e transformação da natureza. Das suas mãos saem borboletas, as quais simbolizam diferentes culturas e coletivos do contexto ibero-americano, compartilhando entre elas, a liberdade; os céus têm as cores da bandeira Colombiana. As borboletas simbolizam os países, como o Brasil, Colômbia, México, Argentina, Chile, Uruguai, Espanha, Costa Rica, Cuba, Paraguai e Peru.

Portanto, é um projeto que procura um diálogo de saberes entre os conhecimentos científicos e os conhecimentos ancestrais, das diversas comunidades. A imagem materializa e reflete a boniteza de Freire (1996, p. 32), no sentido de que educar ou comunicar pressupõe a integração das dimensões estéticas e éticas, que se configuram na busca de costurar diversos mundos, culturas e povos a partir de uma imagem, mantendo a "decência e boniteza de mãos 
Ensino, Saúde e Ambiente - v. 14 n. esp. (2021): Dossiê Paulo Freire para além dos 100 anos: construir utopias, transformar a realidade, p. 685-708.

\section{Estética, Cinema, Teatro, Comunicação}

dadas”. Nessa busca de diálogo os episódios são publicados também em formato de texto escrito (blog), sendo que os primeiros seis episódios foram publicados em parceria com o Laboratório de Limnologia da Universidade Federal do Rio de Janeiro, em espanhol e português, e posteriormente, com a parceria com Friends for Future, esses primeiros seis episódios foram publicados somente em inglês na página deles www.friendsforfuture.eu, e os episódios restantes nos três idiomas.

\section{REFLEXÕES E ENCONTROS COM CONCEITOS FREIRIANOS}

Nesta seção apresentamos os diferentes episódios do programa Ambiente y cotidianidad (Environment and Everyday Life) com base nos elementos que Freire (2020a) estabelece como necessários ou identifica como críticos para uma educação voltada para mudança social. Nesse sentido, se propõe situações comunicativo-educativas freireanas como complemento a esse exercício de ouvir os episódios. Consideramos, nesta perspectiva, que os professores ou pessoas que utilizem os episódios com fins educacionais ou de divulgação científica, uma vez ouvidos, façam um levantamento do universo vocabular e de conceitos chaves, estabelecendo uma relação com as situações comunicativo-educativas freirianas planejadas aqui, criando situações existenciais típicas e estabelecendo relações com as redes de vida dos grupos com quem se trabalha.

\section{O SER HUMANO COMO UM SER DE RELAÇÕES NO MUNDO DA NATUREZA- CULTURA}

\footnotetext{
“a importância de travar relações permanentes com este mundo, de que decorre pelos atos de criação e recriação, o acrescentamento que ele faz ao mundo natural, que não fez, representando na realidade cultural. e de que, nestas relações com a realidade e na realidade, trava o homem uma relação específica, de que resulta o conhecimento que expressa pela linguagem" (Freire, 2020a, p. 137).
}

Mejía-Cáceres e Zambrano (2018, p. 89) identificam como um princípio dos processos da educação ambiental "o reconhecimento do eu, do outro e do oikos desde uma ética ambiental e um sistema de valores ambientais mediante o uso da poética e estética", princípio que deve ser a base nas relações do ser humano, já que este deve reconhecer-se como um ser que coabita com outros seres como ele, humanos, mas também com outros não humanos, mas o que não significa que por isso tenham menor valor ou devam estar ao serviço dele. Desse modo, consideramos que 11 dos episódios publicados até o momento partem das experiências vividas, 
Ensino, Saúde e Ambiente - v. 14 n. esp. (2021): Dossiê Paulo Freire para além dos 100 anos: construir utopias, transformar a realidade, p. 685-708.

\section{Estética, Cinema, Teatro, Comunicação}

dos ideais pessoais e confrontados pelo social, o que forma a identidade do programa; além do que o uso da dialética do reconhecimento nos permite pensarmos em um primeiro momento em nós mesmos como sujeitos em diferentes ambientes, nosso lar (episódio 1, 3, 5, 26), nossa sociedade (episodio 2, 4, 13, 25, 27, 28); mas também em nossas múltiplas identidades (episódio 1, 14).

Como indica Krenak (2019) devemos admitir a natureza como uma imensa multidão de formas que nos inclui, recuperar nossas camadas da natureza que estão em nós, e assim poderemos ter um ethos respeitoso da morada, da nossa casa, reconciliar com a cultura e a natureza a partir de atitudes de respeito, solidariedade e diálogo (NOGUERA, 2004). No quadro 1, apresentamos um conjunto de episódios onde propomos algumas situações comunicativo-educativas que consideramos como situações freirianas as quais os/as educadores podem desenvolver práticas pedagógicas tomando como base os episódios e complementando para recriar ou resgatar nossas relações humano-natureza-cultura.

Quadro 1: Episódios sobre o ser humano como um ser de relações no mundo de natureza-cultura

\begin{tabular}{|c|c|c|}
\hline Ep & Título & Síntese do episódio \\
\hline 1 & $\begin{array}{c}\text { O que o lixo de tua casa } \\
\text { diz }\end{array}$ & $\begin{array}{l}\text { Neste episódio narra-se o tipo de lixo que se produz numa casa determinada, e se } \\
\text { reflexiona como ele pode estar vinculado ao sistema (desigualdade ao acesso de agua } \\
\text { potable, problemas de saneamiento), à saúde (alimentação saudável, doenças associadas } \\
\text { à água potável e a uma mala alimentação), à cultura (consumo de acordo a nossas } \\
\text { costumes) e ao ambiente (resíduos, desechos, reciclagem, reutilização). }\end{array}$ \\
\hline 5 & $\begin{array}{l}\text { Dicas para o uso de } \\
\text { máscaras }\end{array}$ & $\begin{array}{l}\text { Neste episódio se dialoga com uma professora universitária da área de saúde, que aborda } \\
\text { as diferentes máscaras que existem de uso público, porque são importantes na proteção } \\
\text { do COVID-19; como usar e quais são os erros mais frequentes, qual é o tratamento que } \\
\text { devemos fazer depois do uso das máscaras. }\end{array}$ \\
\hline 28 & $\begin{array}{l}\text { Transformando nossa } \\
\text { relação com o ambiente }\end{array}$ & $\begin{array}{l}\text { O convidado explica como a relação humano -natureza pode gerar crises. De se recriar, } \\
\text { se revelar nas redes da vida, no território. Deixar a tradição mercantilista como vínculo } \\
\text { de nossa cultura com a natureza. }\end{array}$ \\
\hline 2 & $\begin{array}{c}\text { Atividades para crianças } \\
\text { e jovens }\end{array}$ & $\begin{array}{l}\text { Se propõe uma atividade para criar ou recriar a realidade de jovens mediante a arte e } \\
\text { posteriormente discutir aspectos da sociedade, características socioambientais (impactos } \\
\text { vs natureza intocada), refletir sobre a relação homem-natureza, materialidade e } \\
\text { espiritualidade }\end{array}$ \\
\hline 3 & $\begin{array}{l}\text { Como ser mais } \\
\text { sustentável }\end{array}$ & $\begin{array}{l}\text { Neste episódio tem um professor universitário convidado e se fazem três perguntas: o que } \\
\text { é e porque é importante a sustentabilidade? Que hábitos incluir em nosso dia a dia para } \\
\text { ser mais sustentáveis? Como podemos incluir nossa família nesta nova cultura? }\end{array}$ \\
\hline 13 & Empregos verdes & $\begin{array}{l}\text { Dialogamos com a perspetiva laboral, considerando que o mercado laboral também deve } \\
\text { ser um ator que considere os aspectos ambientais, e devem ter uma responsabilidade } \\
\text { social e ambiental. }\end{array}$ \\
\hline
\end{tabular}


Ensino, Saúde e Ambiente - v. 14 n. esp. (2021): Dossiê Paulo Freire para além dos 100 anos: construir utopias, transformar a realidade, p. 685-708.

\section{Estética, Cinema, Teatro, Comunicação}

\begin{tabular}{|c|c|l|}
\hline 26 & $\begin{array}{c}\text { Consumo Responsável e } \\
\text { Mudança Climática }\end{array}$ & $\begin{array}{l}\text { Nesse episódio, se dialoga com um convidado sobre como mudar nosso consumo, porque } \\
\text { este afeta o meio ambiente e contribui para a mudança climática. O convidado explica o } \\
\text { que é a pegada do Carbono em relação ao nosso consumo e da dicas de como podemos } \\
\text { ter um consumo responsável. }\end{array}$ \\
\hline 4 & $\begin{array}{c}\text { Como avaliar a } \\
\text { informação que } \\
\text { recebemos através das } \\
\text { redes sociais? }\end{array}$ & $\begin{array}{l}\text { Dado a quantidade de fake news, o episódio inicia fazendo referência a indústria cultural } \\
\text { e o capital. posteriormente, se fala da importância de verificar informações, comparar com } \\
\text { a ciência e o contexto. }\end{array}$ \\
\hline 16 & $\begin{array}{c}\text { Habilidade para a vida, } \\
\text { inteligência intrapessoal } \\
\text { e interpessoal }\end{array}$ & $\begin{array}{l}\text { As múltiplas inteligências de Howard Gardner. Se enfoca posteriormente na inteligência } \\
\text { intrapessoal, como parte de um primeiro nível da educação ambiental, estar bem consigo } \\
\text { mesmo para depois melhorar a relação com outro. }\end{array}$ \\
\hline 25 & $\begin{array}{c}\text { Fenômenos Associados } \\
\text { às Mudanças Climáticas }\end{array}$ & $\begin{array}{l}\text { Neste episódio se explica o que é a mudança climática e qual é a diferença com o } \\
\text { aquecimento global. }\end{array}$ \\
\hline 27 & $\begin{array}{c}\text { Mudança Climática um } \\
\text { problema político? }\end{array}$ & $\begin{array}{l}\text { Este episódio dialoga com um assessor parlamentar, e se pergunta: por que a mudança } \\
\text { climática é um problema político? Quais são as pessoas mais afetadas pela mudança } \\
\text { climática? Como os cidadãos podem contribuir na luta contra a mudança climática. }\end{array}$ \\
\hline
\end{tabular}

Para complementar o uso do podcast dentro da sala de aula dos episódios 1,5 e 28, considerando a perspectiva freiriana, se recomenda aos/as educadores utilizar o background cultural (formas de proceder, percepção da realidade) como unidade pedagógica; posteriormente discutir o ser humano como um ser de relações no mundo de natureza-cultura, cujas ações têm impactos positivos ou negativos a nível local, regional e mundial. Para o uso do episódio 2 se pode discutir o ser humano como um ser criador e recriador na realidade e na compreensão dela, e interpretar a manifestação poética-estética da obra de arte. No uso dos episódios 3, 13, 26 o/a educador/a pode problematizar a imagem do sujeito consumidor em detrimento da imagem do cidadão; trazer ao diálogo o ato de "esperançar" e transformar nossos hábitos depredadores que geram a mudança climática e novas pandemias e debater sobre a diversidade como unidade, considerar a coincidência dos objetivos da luta.

Com o episódio 4, pode-se usar a categoria freiriana do saber superado como ignorância, mediante o uso da luta contra negacionismo e fake news como unidade pedagógica; e questionar a propaganda ideológica, política ou comercial. Com o episódio 16 e a partir das categorias freirianas de diversidade e amor (FREIRE, 2020b) na prática educativa, podem-se abordar como se reconhecer as diferenças entre as pessoas para construir algo coletivo, e de intercomunicação íntima de duas consciências que se respeitam. E com os episódios 25 e 27 pode-se discutir o papel do ser humano como um acelerador dos problemas ambientais e a partir 
Ensino, Saúde e Ambiente - v. 14 n. esp. (2021): Dossiê Paulo Freire para além dos 100 anos: construir utopias, transformar a realidade, p. 685-708.

\section{Estética, Cinema, Teatro, Comunicação}

de experiências de vida, utilizar o background cultural para exemplificar situações de injustiça socioambiental.

\section{DE UMA EDUCAÇÃO BANCÁRIA A UMA EDUCAÇÃO DIALÓGICA}

Como se indicou anteriormente, os humanos se constituem na arena do diálogo, mediatizados pelo mundo no exercício da palavra, e por isso para Freire a dialogicidade é uma exigência epistemológica da e essencial no exercício da democracia (FREIRE, 2013).

$\mathrm{Na}$ ação dialógica "os sujeitos se encontram para a transformação do mundo em colaboração" (FREIRE, 2016, p.227), isso implica também uma dialética do reconhecimento ou alteridade, na qual a identidade se produz no jogo de identificações e com a diferenciação no processo diferenciante (FERNÁNDEZ, 2008), em outras palavras,, Mejía-Cáceres e Zambrano (2018) afirmam:

Para o estabelecimento de relações entre as diferenças é necessário a construção de um sistema de valores, no qual participem a vontade, o amor, a paixão por construir um diálogo, a compreensão do outro e justiça (p. 90).

Adicionalmente, a ação dialógica implica problematizar, ou seja, uma análise crítica sobre a realidade problema, também se obriga a união dos oprimidos entre si, e deles com ela; implica também a organização das massas populares; e a síntese cultural, na qual a realidade a ser transformada é a incidência da ação dos atores (FREIRE, 2016). No quadro 2, apresentamos alguns episódios, suas descrições e posteriormente, estabeleceremos as situações comunicativo-pedagógicas.

Quadro 2: De uma educação bancária a uma educação dialógica

\begin{tabular}{|c|l|l|}
\hline Ep & \multicolumn{1}{|c|}{ Título } & \multicolumn{1}{c|}{ Síntese do episódio } \\
\hline 6 & $\begin{array}{l}\text { Reflexões desde a } \\
\text { Educação Ambiental } \\
\text { em tempos de } \\
\text { pandemia }\end{array}$ & $\begin{array}{l}\text { Neste episódio se dialoga com uma professora universitária sobre projetos de educação } \\
\text { ambiental sobre os estudos críticos do discurso e a pedagogia de Paulo Freire, o que permite } \\
\text { perceber os problemas socioambientais associados às diferenças de poder e desigualdades } \\
\text { sociais }\end{array}$ \\
\hline 8 & $\begin{array}{l}\text { A importância da } \\
\text { educação de base } \\
\text { comunitária }\end{array}$ & $\begin{array}{l}\text { Este episódio tem um professor universitário convidado que explica a importância da educação } \\
\text { comunitária no diálogo com o território, mediante o diálogo com a ecologia de saberes, para } \\
\text { reconhecer os saberes locais, os mestres, maestrinas dos saberes locais, compreender que o } \\
\text { saber dinâmico e territorializado possibilita um acesso a uma educação contextualizada às } \\
\text { realidades locais. }\end{array}$ \\
\hline 17 & $\begin{array}{l}\text { Educação ambiental: } \\
\text { Uma experiência no } \\
\text { Chile }\end{array}$ & $\begin{array}{l}\text { Este episódio tem como convidado um professor do Chile, que fala sobre a educação ambiental } \\
\text { neste país e a criação de programas comunitários de educação ambiental para responder às } \\
\text { necessidades territoriais. }\end{array}$ \\
\hline
\end{tabular}


Ensino, Saúde e Ambiente - v. 14 n. esp. (2021): Dossiê Paulo Freire para além dos 100 anos: construir utopias, transformar a realidade, p. 685-708.

Estética, Cinema, Teatro, Comunicação

\begin{tabular}{|c|l|l|}
\hline 23 & $\begin{array}{l}\text { Concepções sobre } \\
\text { pesticidas }\end{array}$ & $\begin{array}{l}\text { A convidada fala de uma pesquisa realizada sobre as crenças, interesses, e experiências de } \\
\text { estudantes de um programa de licenciatura sobre o uso de agrotóxicos. }\end{array}$ \\
\hline 24 & $\begin{array}{l}\text { Fridays for Future: } \\
\text { Uma experiência no } \\
\text { Brasil }\end{array}$ & $\begin{array}{l}\text { Este episódio dialoga com uma professora mediante as perguntas: porque é importante } \\
\text { participar em ações contra a mudaça climática? Que tipo de ações conhece e tem participado } \\
\text { contra a luta da mudança climática? Como a comunidade tem reagido às ações feitas com os } \\
\text { estudantes? }\end{array}$ \\
\hline
\end{tabular}

O/a educador/a pode trabalhar como uma unidade pedagógica a "consciência bancária" da educação, para isso pode discutir a passividade do/a estudante na construção de conhecimento e a superioridade do/a educador/a, mediante os episódios 6 e 8 pode discutir como as comunidades têm um conhecimento que é válido e que deve ser reconhecido, trazer ao debate a diferença entre ter um conhecimento teórico e um conhecimento prático, como articular os dois tipos de conhecimentos para desenvolver a capacidade de criação do homem, e da transformação. Com os episódios 17, 23 e 24 pode se discutir o conceito de sociedade em transição, como as concepções estão em constante mudança, e as características de uma sociedade fechada, a qual procura a continuação do status ou privilégio. Estes dois conceitos podem ser vinculados a discutir aspectos relacionados às injustiças socioambientais e as pautas dos movimentos sociais.

\section{DESENVOLVER UMA CONSCIÊNCIA CRÍTICA NA BUSCA DA TRANSFORMAÇÃO DA REALIDADE A PARTIR DA ATIVIDADE CRIADORA}

O desenvolvimento de uma consciência crítica que permite ao homem transformar a realidade se faz cada vez mais urgente. Na medida em que os homens, dentro de sua sociedade, vão respondendo aos desafios do mundo, vão temporalizando os espaços geográficos e vão fazendo história pela sua própria atividade criadora (FREIRE, 2020b, p. 41)

Segundo Freire (2020b), todo ser humano tem um ímpeto criador, e nesse sentido, a educação tem um papel muito importante no processo de desenvolver esse ímpeto, implicando portanto, em recusar a domesticação, sendo necessário desenvolver uma consciência crítica para transformar a realidade. Essa transformação pode-se dar mediante o discurso, já que através dele "os/as sujeitos/as interagem, participam, interpretam, fazem oposição ou apoiam 
Ensino, Saúde e Ambiente - v. 14 n. esp. (2021): Dossiê Paulo Freire para além dos 100 anos: construir utopias, transformar a realidade, p. 685-708.

\section{Estética, Cinema, Teatro, Comunicação}

processos sociais e ao mesmo tempo, propõem elementos no domínio do realizado, eventos ou atividades" (MEJÍA-CÁCERES; FREIRE, 2020, p. 241).

Considerando essa capacidade criadora manifestada em eventos mediante os discursos, a possibilidade de gerar pontos de pausa nas relações hegemônicas é um fato. A influência ou não do evento dependerá de como está estruturada a interação social, ou seja, participantes, identidades, papéis, conhecimentos, ideologias, entre outros (VAN DIJK, 2016). Freire (2020b) estabeleceu algumas características da consciência crítica, as quais podemos aplicar num evento de comunicação o que nos permitiria criar pontos de quebra em relações hegemônicas e que, portanto, nós podemos utilizar como situações comunicativo-educativas. No quadro 3 identificamos alguns episódios que poderemos usar para discutir as características da consciência crítica de Freire como unidades pedagógicas.

Quadro 3: De uma consciência ingênua a uma consciência crítica.

\begin{tabular}{|c|c|c|}
\hline $\mathbf{E p}$ & Título & Síntese do episódio \\
\hline 7 & $\begin{array}{l}\text { Mulheres em tempos } \\
\text { de COVID-19 }\end{array}$ & $\begin{array}{l}\text { Este episódio é um monólogo, no qual se reflete sobre violência de gênero e / ou } \\
\text { doméstica. O aumento de casos de violência e feminicídios na quarentena do COVID- } \\
19 \text {, e algumas estratégias de ajuda ao sofrer violência de gênero, assim como código para } \\
\text { solicitar assistência segundo o país. }\end{array}$ \\
\hline 9 & $\begin{array}{l}\text { Mês do } \\
\text { empoderamento } \\
\text { feminino }\end{array}$ & $\begin{array}{l}\text { Se explica para os ouvintes porque o podcast aborda aspectos relacionados à violência } \\
\text { de gênero e, desta vez, sobre o empoderamento das mulheres. Na agenda de } 2030 \text { para o } \\
\text { desenvolvimento sustentável proposta pela UNESCO, encontramos um dos objetivos } \\
\text { para alcançar a igualdade de gênero e empoderar todas as mulheres e meninas. Mas, } \\
\text { principalmente porque somente dessa maneira podem ser estabelecidas sociedades mais } \\
\text { justas. }\end{array}$ \\
\hline 10 & $\begin{array}{l}\text { A mulher pode ser } \\
\text { uma profissional } \\
\text { independentemente } \\
\text { de sua origem étnico- } \\
\text { racial }\end{array}$ & $\begin{array}{l}\text { Este episódio contou com a participação de três mulheres convidadas, duas mulheres } \\
\text { indígenas e uma mulher negra. As mesmas responderam às perguntas: O que significa } \\
\text { ser indígena ou negra em uma sociedade ocidental? Por que não devemos permitir que } \\
\text { nossa origem étnico-racial seja um obstáculo para ser um profissional? E, finalmente, } \\
\text { deixaram uma mensagem para as mulheres. }\end{array}$ \\
\hline 11 & $\begin{array}{l}\text { A mulher pode } \\
\text { participar na política }\end{array}$ & $\begin{array}{l}\text { Este episódio tem três convidadas para dialogarem sobre a participação da mulher na } \\
\text { política, daí que uma convidada é a primeira mulher indígena prefeita em } 200 \text { anos, a } \\
\text { segunda convidada é a subdiretora de políticas e planos ambientais da Colômbia e a } \\
\text { terceira é uma mulher indígena co-deputada no Brasil. }\end{array}$ \\
\hline 12 & $\begin{array}{l}\text { A mulher poder se o } \\
\text { que ela quiser }\end{array}$ & $\begin{array}{l}\text { Neste episódio as convidadas não compartilham a área de trabalho, mas que são } \\
\text { inspirações para outras mulheres, a primeira é uma professora negra universitária que } \\
\text { fala da importância das agendas de mulheres negras em espaços acadêmicos, a segunda } \\
\text { convidada é uma mulher colombiana empresária em países desenvolvidos. }\end{array}$ \\
\hline
\end{tabular}


Ensino, Saúde e Ambiente - v. 14 n. esp. (2021): Dossiê Paulo Freire para além dos 100 anos: construir utopias, transformar a realidade, p. 685-708.

Estética, Cinema, Teatro, Comunicação

\begin{tabular}{|c|l|l|}
\hline 14 & $\begin{array}{l}\text { A sociedade que o } \\
\text { COVID-19 revela: O } \\
\text { caso latino- } \\
\text { americano }\end{array}$ & $\begin{array}{l}\text { Este episódio é um monólogo sobre os impactos da COVID-19 na sociedade, se reflete } \\
\text { sobre as contradições adjacentes ao capitalismo e, portanto, as tensões geradas pela } \\
\text { COVID-19 entre saúde e economia. }\end{array}$ \\
\hline 15 & $\begin{array}{l}\text { A libertação da mãe } \\
\text { terra }\end{array}$ & $\begin{array}{l}\text { Este episódio é um monólogo, o qual fala sobre os movimentos sociais para proteger a } \\
\text { natureza pelos indígenas, se exemplifica o modelo do Bom viver da Bolívia, o } \\
\text { movimento da liberação da mãe terra da monocultura da cana de açúcar pelas } \\
\text { comunidades Nasa na Colômbia, entre outros, e a falta de vontade política para apoiar as } \\
\text { comunidades na proteção do ambiente. }\end{array}$ \\
\hline
\end{tabular}

A primeira característica estabelecida por Freire (2020b, p. 53) é "Anseio de profundidade na análise de problemas. Não se satisfaz com as aparências. Pode-se reconhecer desprovida de meios para análise do problema”. Desse modo, podemos estabelecer relação com os episódios 7, 14 e 15, os quais introduzem um problema social, mas que a complexidade do dito problema não pode ser desenvolvida nesse episódio, mas que pode ser usado como provocação, portanto, o professor pode usar como introdução e estabelecer conjuntamente com os estudantes critérios de análise.

Podemos trazer o episódio 10 e 11 para articular a segunda característica "reconhecer que a realidade é mutável". O/A educador/a pode fazer a ligação com a história para discutir como os povos indígenas e afrodescendentes têm sofrido opressões através dos tempos e ao mesmo tempo, mostrar a conquista de direitos resultado das lutas, e exemplificar com o episódio 11, a possibilidade de mudanças ao ter a fala de uma mulher indígena eleita prefeita de uma cidade depois de 200 anos de patriarcado.

Adicionalmente, os episódios 9, 10, 11, 12 concentram-se na abordagem do empoderamento feminino, mediante exemplos de mulheres que lutam contra preconceitos, refutando a ideia de que a mulher deve ser somente "dona de casa", permitindo trabalhar uma característica da consciência crítica defendida por Freire, sobre a possibilidade de livrar-se de preconceitos (FREIRE, 2020b). Como exemplo de abordagem educativa, o/a educador/a poderá complementar a discussão com exemplos e situações sociológicas próprias do contexto do/a estudante. 
Ensino, Saúde e Ambiente - v. 14 n. esp. (2021): Dossiê Paulo Freire para além dos 100 anos: construir utopias, transformar a realidade, p. 685-708.

Estética, Cinema, Teatro, Comunicação

\title{
EDUCAÇÃO COMO PRÁTICA DA LIBERDADE: DE UMA SOCIEDADE ALIENADA A UMA SOCIEDADE EM TRANSIÇÃO
}

\begin{abstract}
A ideia de colonialidade está atrelada ao projeto de colonialismo ou colonização, numa perspectiva mais ampla. Diz respeito ao processo de dominação entre grupos sociais, estabelecendo uma relação de superioridade daquela que domina sobre o dominado, a ponto de suplantar seus conhecimentos, sua cultura, sua identidade e porque não dizer, a sua humanidade (DUTRA; CASTRO; MONTEIRO, 2019, p.2)
\end{abstract}

Segundo Freire (2020b) a sociedade alienada se baseia na imitação servil de outras culturas, e desse modo, não existe consciência do próprio existir, não existe uma consciência crítica. Nesta sociedade é comum a violência dos opressores, como afirma Meneses (2019) no domínio da cultura ela se dá no campo da educação, em suas palavras "a colonização tem atuado através de processos de violenta intervenção política e epistemológica, os quais resultaram na suspensão do crescimento orgânico das instituições e das histórias dos colonizados" (p.20). Entretanto, as sociedades podem buscar a desalienação mediante o surgimento de novos valores. Quando as massas passam de espectadoras passivas a um estado de democratização, elas começam a exigir participação mediante mais educação, o que Freire chama de educação de massa na correspondência entre a manifestação das massas e a reivindicação. "Quanto mais as massas populares desvelam a realidade objetiva e desafiadora sobre a qual elas devem incidir sua ação transformadora, tanto mais se "inserem" nela criticamente" (2016, p 54). O programa podcast trouxe em alguns de seus episódios elementos da história, que para muitos é naturalizada ou irrelevante, e que pode ser considerada como um processo que permite avançar nos caminhos do movimento da decolonialidade, a partir da educação.

Quadro 4: De uma sociedade alienada e invadida culturalmente a uma sociedade com pensamento decolonial.

\begin{tabular}{|c|l|l|}
\hline Ep & \multicolumn{1}{|c|}{ Título } & \multicolumn{1}{c|}{ Síntese do episódio } \\
\hline 18 & $\begin{array}{l}\text { Entendendo a } \\
\text { decolonialidade }\end{array}$ & $\begin{array}{l}\text { Temos como convidado um professor universitário ao qual se fez as perguntas: ainda } \\
\text { existe colonialidade? o que é decolonialidade? como podemos trazer em nosso dia a dia? }\end{array}$ \\
\hline 19 & $\begin{array}{l}\text { Discutindo a } \\
\text { decolonialidade do } \\
\text { ser e do viver }\end{array}$ & $\begin{array}{l}\text { Este episódio tem como convidada uma professora universitária que responde às } \\
\text { perguntas o que seria a colonialidade do ser e do viver? e o que podemos fazer em nosso } \\
\text { dia a dia para descolonizar o ser e o viver? }\end{array}$ \\
\hline 20 & $\begin{array}{l}\text { Colonialidade no } \\
\text { México }\end{array}$ & $\begin{array}{l}\text { Este episódio tem como convidado um integrante da comunidade do pensamento } \\
\text { decolonial no México, a quem se perguntou: quais são as marcas de colonialidade no } \\
\text { México? Quais são as expressões de resistência? Como tem se desenvolvido os processos }\end{array}$ \\
\hline
\end{tabular}


Ensino, Saúde e Ambiente - v. 14 n. esp. (2021): Dossiê Paulo Freire para além dos 100 anos: construir utopias, transformar a realidade, p. 685-708.

Estética, Cinema, Teatro, Comunicação

\begin{tabular}{|c|l|l|}
\hline 21 & $\begin{array}{l}\text { Um olhar da História } \\
\text { à Colonização }\end{array}$ & $\begin{array}{l}\text { Tecoloniais no México? } \\
\text { processo de colonização, o professor desenvolve seu discurso iniciando desde os tempos } \\
\text { medievais, para explicar como a reforma luterana transforma o ocidente e ajuda a pensar } \\
\text { o mito da modernidade. }\end{array}$ \\
\hline 22 & $\begin{array}{l}\text { As Revoluções } \\
\text { Científicas: Por que } \\
\text { são do Ocidente e } \\
\text { não de Oriente? }\end{array}$ & $\begin{array}{l}\text { Temos como convidado um professor universitário ao qual se pergunta por que a maioria } \\
\text { dos conhecimentos se produzem no ocidente (norte)? a desumanidade é produto de que? } \\
\text { e qual é o papel da religião na colonização? }\end{array}$ \\
\hline
\end{tabular}

Os episódios 18, 19, 20, 21 e 22 acompanhados da orientação do/a educador/a, podem ser usados sobre a discussão de ter um aprofundamento da sua tomada de consciência da realidade para gerar ações concretas. Fazer uso de um diálogo de saberes permitirá aprofundar em certos conhecimentos discutidos pelos/as convidados/as dos episódios. Freire insistiu na ação, não em explicar às massas, mas em dialogar com elas sobre as suas ações.

O/a educador/a pode associar como unidade pedagógica a "invasão cultural" assim como, a relação "sujeito-objeto" próprio de relações de dominação, até chegar a revolução cultural, a ação cultural dialógica, abordando conceitos de cultura, transformação cultural, colaboração, união, organização e síntese cultural.

\section{CONSIDERAÇÕES FINAIS}

Ainda que considerando o podcast como uma ferramenta própria da indústria cultural que pode contribuir para a semiformação e a prática colonial, também consideramos seu potencial de comunicação. Nesse sentido, encontramos a possibilidade de utilizar programas de podcast que desde sua concepção têm sido pensados em uma perspectiva latinoamericana, feminista e ambientalista. $\mathrm{O}$ estudo e as ações realizadas permitiram considerar que o podcast pode ser usado como um importante complemento de processos educacionais, neste caso, na abordagem de problemáticas socioambientais tais como: a emergência climática, o ecoetnogenocidio, fragilidade da legislação ambiental, migrações ambientais, demarcações de terras indígenas, entre outras questões.

Reiteramos que considerar o podcast com um projeto dialógico é possível, dado que para Freire, o diálogo possui um caráter dialético-problematizador pois é por meio do diálogo que temos a chance de experimentar o distanciamento necessário para observar o mundo e a nossa própria existência. 
Ensino, Saúde e Ambiente - v. 14 n. esp. (2021): Dossiê Paulo Freire para além dos 100 anos: construir utopias, transformar a realidade, p. 685-708.

\section{Estética, Cinema, Teatro, Comunicação}

A possibilidade de recorrer ao pensamento freiriano e, neste sentido, considerar algumas de suas categorias como fundantes; como a humanização, o diálogo, dialogicidade, a criticidade e a criatividade; desde o planejamento dos episódios de programas de podcast, permite-nos inferir que é viável, a partir do reconhecimento do homem e da mulher como seres de relações que estão no e com o mundo, contribuindo no incremento das conexões e parcerias entre espaços informais e formais e, em processos educativos emancipatórios e libertadores.

A partir do uso de situações comunicativo-educativas freirianas se contribui na interpretação do conhecimento científico como um processo cultural, ao permitir análises dos processos dialógicos no interior dos episódios, assim como, com o contexto do ouvinte. Identificamos a importância de gerar critérios de seleção dos programas de podcast, mas também gerar estratégias educacionais que contribuam na construção de uma postura crítica.

Afinal, se o objetivo é atuarmos na formação de cidadãos e cidadãs críticos e críticas, estes precisam apresentar postura ética de crítica à ordem social pautada na produtividade material que se baseia na exploração do ambiente de modo utilitário e pragmático, bem como na persistência da desigualdade, da exclusão social e ambiental. Ademais, tais cidadãos e cidadãs se caracterizam como seres comprometidos/as com a totalidade da vida em todas as suas formas.

Com esta compreensão, vislumbramos que o projeto podcast Ambiente y Cotidianidad possibilita contribuir para a constituição de atitudes e valores que transformem as relações da sociedade com ela própria e da sociedade com a natureza. E, à luz desse pensamento, compreendemos que educadores/as e podcasters podem se reinventar na busca por conteúdos e metodologias que permitam a transformação social tendo a tecnologia e as linguagens contemporâneas como aliadas dos processos educativos e dos processos de divulgação do conhecimento.

\section{AGRADECIMENTO}

A presente pesquisa foi realizada com apoio da FACEPE (Fundação do Amparo a Ciência e Tecnologia). 
Ensino, Saúde e Ambiente - v. 14 n. esp. (2021): Dossiê Paulo Freire para além dos 100 anos: construir utopias, transformar a realidade, p. 685-708.

Estética, Cinema, Teatro, Comunicação

\section{REFERÊNCIAS}

ADORNO, T. .; HORKHEIMER, M. (1947). Dialéctica do Esclarecimento. Fragmentos Filosóficos. Disponível em: <https://nupese.fe.ufg.br/up/208/o/fil_dialetica_esclarec.pdf $>$. Acesso em: 19 maio de 2021.

DUTRA, D. S. A.; CASTRO, D. J. F. A.; MONTEIRO, B. A. P. . EDUCAÇÃO EM CIÊNCIAS E DECOLONIALIDADE: EM BUSCA DE CAMINHOS OUTROS. In: Bruno A. P. Monteiro; Débora S. A. Dutra; Suzani Cassiani; Celso Sanchez; Roberto D. V. L. Oliveira. (Org.). Decolonialidades na Educação em Ciências (Coleção culturas, direitos humanos e diversidades na educação em ciências). 1ed.São Paulo: Livraria da Física, 2019, v., p. 01-17.

ARISTIZABAL, A. Podcasting: A Preliminary Clasroom Study. GisT Education and Learning Research Journal, p. 30-40, 2009.

BAUMAN, Z. Modernidade Líquida. Rio de Janeiro: Zahar. 2001.

BIERMAN, J. VALENTINO, M. Podcasting initiatives in American research libraries. // Library Hi Tech, v. 29, n.2, p. 349-358, 2011.

BIZZO, N. História da ciência e Ensino da ciência: instrumentos para a prática e a pesquisa escolar. In: BIZZO, N. CHASSOT, A. AMORIM, V. Ensino de Ciências. São Paulo: Summus. 2013, p.13-59.

CASTRO, D. J. F. DE A.; MONTEIRO, B. A. P. A (re)existência de mulheres na forma de saberes ancestrais: repensando outras relações entre ciência, ambiente e educação no contexto pandêmico. Revista Sergipana de Educação Ambiental, v. 7, n. Especial, p. 1-16, 2020. doi.org/10.47401/revisea.v7iEspecial.14425.

FERNÁNDEZ, G. Mismidad y otredad: identidad y diferencia en el mundo contemporáneo. In: Primera Jornadas de Filosofía Política, Democracia, Tolerancia y Libertad. Departamento de humanidades de la Universidad Nacional del Sur (Bahía Blanca). 2008

FREIRE G. Ideias sem fio: Um panorama sobre podcasts no Brasil. Monografia do Curso de Comunicação Organizacional, Faculdade de Comunicação, Universidade de Brasília. 2015.

FREIRE, P. Educação como prática da Liberdade. 48 ed. São Paulo: Paz \& Terra, 2020a.

FREIRE, P. Educação e Mudança. 42 ed. São Paulo: Paz \& Terra, 2020 b.

FREIRE, P. Extensão e Comunicação. 18 ed. São Paulo: Paz \& Terra, 2017.

FREIRE. P. Pedagogia do oprimido. 62 ed. São Paulo: Paz \& Terra, 2016.

FREIRE. P. À sombra desta mangueira. 11 ed. São Paulo: Paz \& Terra, 2013.

FREIRE, P. Pedagogia da autonomia: saberes necessários à prática educativa. 25. ed. Rio de Janeiro: Paz e Terra, 1996.

FREIRE, P. Pedagogia do oprimido.Rio de Janeiro: Paz e Terra, 1987.

FREIRE, P. Educação e Mudança.12. ed. 1 Paz e Terra. Rio de Janeiro, 1979. 
Ensino, Saúde e Ambiente - v. 14 n. esp. (2021): Dossiê Paulo Freire para além dos 100 anos: construir utopias, transformar a realidade, p. 685-708.

\section{Estética, Cinema, Teatro, Comunicação}

GOES, A. Midiatização e plataformização: aproximações. Revista Novos Olhares, v. 8. n. 2, 2019.

JESUS, W. B de. Podcast e educação: um estudo de caso. 2014. 56 f. Dissertação (mestrado) Universidade Estadual Paulista, Instituto de Biociências de Rio Claro, 2014. Disponível em: http://hdl.handle.net/11449/121992

KRENAK, A. Ideias para adiar o fim do mundo. São Paulo: Companhia Letras, 2019.

LANDER. E. Ciências sociais: saberes coloniais e eurocêntricos. In: CLACSO, Consejo Latinoamericano de Ciencias Sociales. A colonialidade do saber: eurocentrismo e ciências sociais. Perspectivas latino-americanas. Buenos Aires: CLACSO, 1993.

MALDONADO-TORRES, N. A Topologia do Ser e a Geopolítica do Conhecimento: modernidade, império e colonialidade. In: SANTOS, B.; MENESES, M. (orgs.). Epistemologias do Sul. Coimbra: Almedina. 2009. p. 337-382.

MARROQUIM, R. Jornalismo e construção social da realidade: o despertar do acontecimento e a composição da notícia. Intercom - Sociedade Brasileira de Estudos Interdisciplinares da Comunicação. XXXIII Congresso Brasileiro de Ciências da Comunicação - Caxias do Sul, RS -2 a 6 de setembro de 2010

MEJÍA-CÁCERES, M.A; FREIRE, L. Eventos Comunicativos de Esperanza en el Contexto de Educación Ambiental en la Formación Inicial de Profesores en Colombia. Ensino, Saúde e Ambiente. Número Especial, p. 239-254, 2020

MEJÍA-CÁCERES, M. A.; ZAMBRANO, A. C. Ciencias, Cultura y Educación Ambiental: Una propuesta para los educadores. Cali: Programa Editorial Universidad del Valle, 2018.

MENESES, M. Os Desafios do Sul: traduções interculturais e interpolíticas entre saberes multilocais para amplificar a descolonização da educação. In: MONTEIRO, B; DUTRA D; CASSIANI S; SÁNCHEZ, C; OLIVEIRA R. Decolonialidades na Educação em Ciências. São Paulo: Livraria da Física, 2019, p. 19-43.

NATAATMADJA, I; DYSON; L. The Role of Podcasts in Students's Learning. International Journal of Interactive Mobile technologies (iJIMT), v. 2, n.3, p. 17-21, 2008.

NOGUERA, A. P. El Reencantamiento del Mundo. México: Programa de las Naciones Unidas para el Medio Ambiente-PNUMA, 2004.

POLLOCK, J. Web Semântica para leigos. Alta Books. Rio de Janeiro. 2010.

QUIJANO, A. Colonialidade do poder e classificação social. In: SANTOS, Boaventura de Sousa; MENESES, Maria Paula. (Org.). Epistemologias do sul. Coimbra: Almedina, 2010. p. 73-116.

QUIÑONEZ, S.A. Defensa ambiental, derechos humanos y ecogenoetnocidio afrocolombiano. In: Pesquisa em Educação Ambiental. v.13, n.1, p.10-27, 2018. Disponível em: http://dx.doi.org/10.18675/2177-580X.vol13.n1.p10-27. Acesso em: 09 ago. 2020.

RAJIC, S. Educational Used of Podcasts. The Fourth International Conference on e-Learning. Belgrade, Serbia, Proceedings, p. 90-94. 2013. 
Ensino, Saúde e Ambiente - v. 14 n. esp. (2021): Dossiê Paulo Freire para além dos 100 anos: construir utopias, transformar a realidade, p. 685-708.

Estética, Cinema, Teatro, Comunicação

TROMBETTA, S; TROMBETTA, L. Inacabamento. In: STRECK, Danilo R., REDIN, Euclides, ZITKOSKI, Jaime José (Org.). Dicionário Paulo Freire. Belo Horizonte: Autêntica, 2010, p 221-222.

VAN DIJK, T. Análisis Crítico del Discurso. Revista Austral de Ciencias Sociales, n. 30, p. 203-222, 2016.

\section{SOBRE AS AUTORAS E O AUTOR}

\section{MARIA ANGÉLICA MEJÍA- CÁCERES}

Programa de Pós-graduação em Ensino das Ciências, Universidade Federal Rural do Pernambuco, Recife, Brasil. Doutor em Educação em Ciências e Saúde (NUTES/UFRJ). Pósdoutoranda no PPGEC da UFRPE. Mestre em Educação com ênfase no ensino das ciências (Universidad del Valle, Colombia). Especialista em Gestão Social (PUC, Cali). Licenciada em Educação Básica com ênfase em Ciências Naturais e Educação Ambiental (Universidad del Valle, Colombia). Pesquisadora em Educação em Ciências e Educação Ambiental, com ênfase na formação de professores, análise do discurso e análise de políticas educacionais.

\section{BRUNO ANDRADE PINTO MONTEIRO}

Programa de Pós-Graduação em Educação em Ciências e Saúde (NUTES/UFRJ) e Mestrado Profissional em Ensino de Química (PEQUI/UFRJ). Doutor em Educação em Ciências e Saúde (NUTES/UFRJ). Mestre em Tecnologia Educacional nas Ciências da Saúde (NUTES/ UFRJ). Licenciado em Química (UFRJ) e em Física (UNIS). Professor Associado da Universidade Federal do Rio de Janeiro (UFRJ/Macaé). Pesquisas no campo da educação e divulgação em Ciências, com ênfase nas temáticas de formação de professores, decolonialidade, direitos humanos, interculturalidade, educação ambiental, mídias, espaços escolares, não escolares.

\section{MONICA LOPES FOLENA ARAÚJO}

Programa de Pós-graduação em Ensino das Ciências, Universidade Federal Rural do Pernambuco, Recife, Brasil. Doutora em Educação (UFPE), Pós-doutora em Educação (UFS), Mestre em Ensino das Ciências (UFRPE) e Licenciada e Bacharel em Ciências Biológicas (UFRRJ). Professora da Universidade Federal Rural de Pernambuco. Líder do Grupo de Pesquisa em Formação e Prática Pedagógica de Professores de Ciências e Biologia (FORBIO) e Coordenadora da Cátedra Paulo Freire da UFRPE. Desenvolve pesquisas no campo da formação e prática pedagógica de professores, educação ambiental e ensino de ciências e biologia. 